\title{
A simple and easy in vitro model to test the efficacy of IV lines' needleless connectors against contamination
}

\author{
María Guembe ${ }^{1 *}$, María Jesús Pérez-Granda, ${ }^{3,4}$ Luis Alcalá1, Pablo Martín-Rabadán 1,2,3 and Emilio Bouza 1,2,3
}

* Correspondence:
mariaguembe@hotmail.com
'Department of Clinical
Microbiology and Infectious
Diseases, Hospital General
Universitario Gregorio Marañón,
C/ Dr. Esquerdo, 46, 28007 Madrid,
Spain
Full list of author information is
available at the end of the article

Results: Overall, all bottles in the control group were negative at the end of the incubation time. In the three contamination experiments, almost all (38/40) bottles were positive during the incubation time. We only found differences regarding the median time to positivity (interquartile range $(\mathrm{IQR})$ ) between saline and propofol in the manipulation with SA 0.05 MF: 240 h (154.82 to 360.00) vs. 66 h (58.01 to 69.11), $p=0.008$.

Conclusions: A daily connector handling with 0.05 McFarland S. aureus solution while instilling saline proved to be a useful model lasting long enough to be used for the comparison of the efficacy of different types of closed needleless connectors against contamination.

Keywords: Catheter colonization; Needleless connector; In vitro contamination; Manipulation model 


\section{Background}

Intravascular catheters are widely used and are indispensable for proper patient management. However, its use implies several risks, which are mainly infectious. Catheter-related bloodstream infection (C-RBSI) is the more important entity which is associated to high rates of morbidity, mortality, and sanitary costs [1].

In general, in those catheters that are inserted for more than 8 days, infection is mainly acquired by an intra-luminal route (66\%) because of hub contamination. Hub colonization after manipulation is responsible for $29 \%$ to $60 \%$ of catheter-related infections (CRI) [2].

Recently, it has been shown that the use of closed needleless connectors is effective against microorganism penetration by hub contamination. Some studies tested the in vitro efficacy of different needleless access devices to prevent the ingress of microorganisms [3-8]. However, these studies have heterogeneous designs, and they are all performed by instilling high concentrations of microorganisms through the catheter.

Our study purpose was to create an in vitro model lasting long enough be used to compare various connectors simulating the real daily handling of these devices based on blood culture bottles.

\section{Methods}

\section{Setting}

This in vitro study has being carried out in the Laboratory of the Clinical Microbiology and Infectious Disease Department of the Hospital General Universitario Gregorio Marañón.

\section{Study design}

The model consisted of 40 blood culture bottles with a peripheral venous cannula inserted under sterile conditions and left in place (Figure 1). In each bottle, a disinfectable needle-free closed connector (CLAVE ${ }^{\mathrm{Tm}}$, CareFusion, Spain) was used to close the cannulas. Twice a day, each cannula was manipulated while instilling $1 \mathrm{~mL}$ of either sterile saline or propofol. Manipulation of the bottles was divided into four models: ten bottles (five saline, five propofol) were manipulated with clean gloves and disinfecting the connector with alcohol (controls), ten bottles (five saline, five propofol) were manipulated without gloves (hands), ten bottles (five saline, five propofol) were manipulated with gloves impregnated with a 0.5 McFarland ATCC 29213 Staphylococcus aureus solution, and ten bottles (five saline, five propofol) were manipulated with gloves impregnated with a 0.05 McFarland ATCC 29213 S. aureus solution. Additional photograph files show this in more detail (see Additional files 1 and 2).

Before handling the connectors in the hand model, a base count and phenotypic identification of the colonizing microorganisms on the manipulators' hands were performed until the bottles became positive.

\section{Laboratory procedure}

The bottles were incubated in a BACTEC 9120 System (Becton Dickinson Microbiology Systems, Maryland, DE, USA) up to 10 days at $37^{\circ} \mathrm{C}$ under continuous agitation. Each day, it was observed whether there was positivity in the bottle fluid (alert from the BACTEC 9120), and in case it occurred, $100 \mu \mathrm{L}$ of the fluid was cultured into the blood, MacConkey, and Brucella agar and incubated under aerobic and anaerobic conditions for $48 \mathrm{~h}$ at $37^{\circ} \mathrm{C}$. Microorganism identification was performed using standard procedures [9]. 


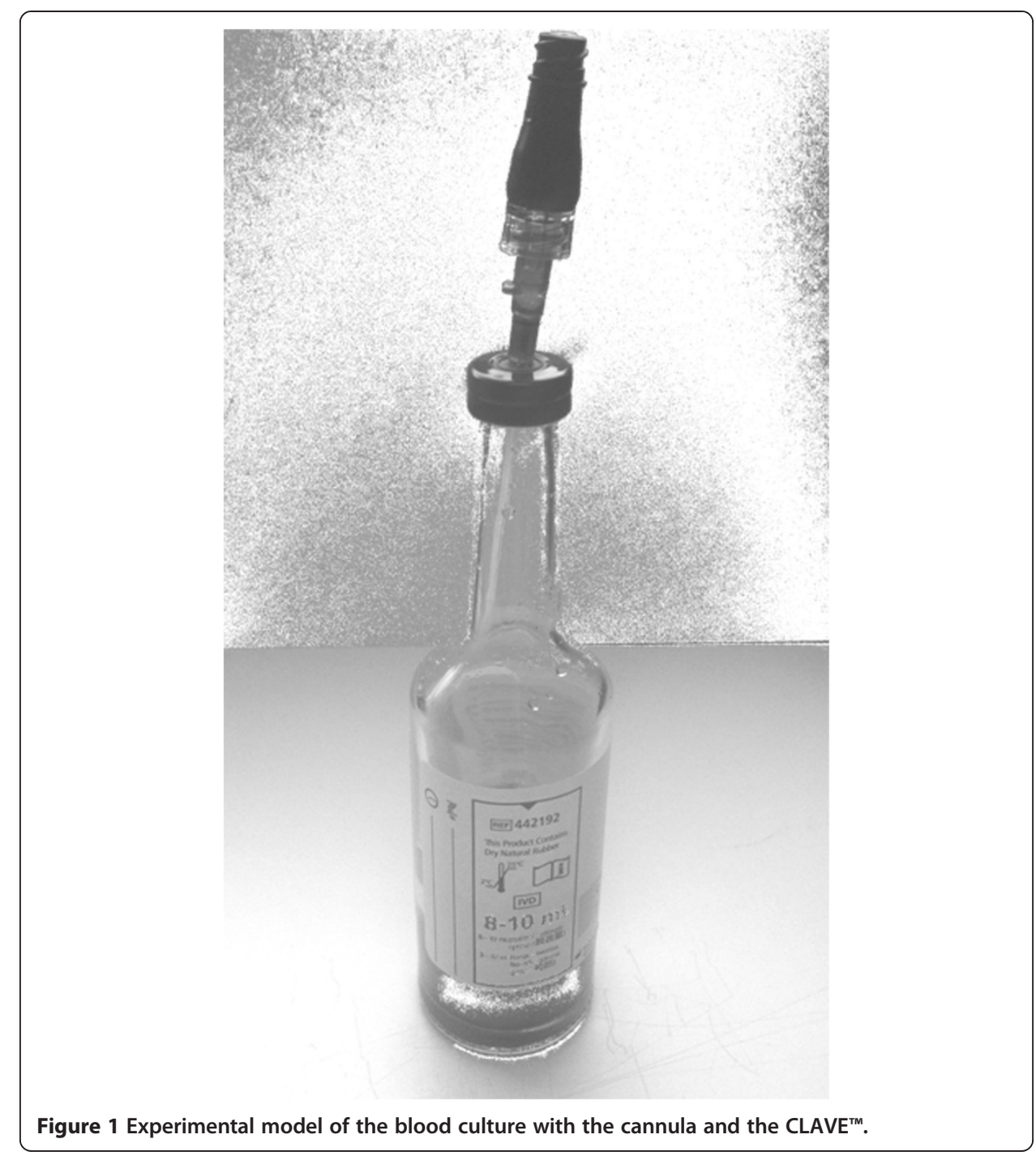

At the end of the incubation time (10 days, $20 \mathrm{~mL}$ ), the negative bottles were also tested by culturing $100 \mu \mathrm{L}$ of the fluid into the blood, MacConkey, and Brucella agar and incubated under aerobic and anaerobic conditions for $48 \mathrm{~h}$ at $37^{\circ} \mathrm{C}$.

The different study variables were annotated in a data collection form.

\section{Statistical analysis}

The qualitative variables appear with their frequency distribution. The quantitative variables are summarized as the median with interquartile range (IQR). Continuous variables were compared using the median test for non-normally distributed variables. The chi-square or Fisher exact test was used to compare categorical variables.

The Kaplan-Meier survival curve was used to compare the time to positivity with the degree of contamination.

All statistical tests were two-tailed. Statistical significance was set at $p<0.05$ for all the tests. The statistical analysis was performed with SPSS 18.0. 
Ethics

This experimental design does not include human subjects and does not use human tissue or samples, so it was exempt from approval of the local ethics committee.

\section{Results and discussion}

Overall, all bottles in the control group were negative at the end of the incubation time. In contrast, almost all bottles (38/40) in the three contamination experiments were positive during the incubation time. In the hand model with saline, we recovered the same Staphylococcus epidermidis strain in four out of the five bottles, which was phenotypically coincident with that isolated from the manipulators' hands. In the remaining bottle, we recovered a Staphylococcus warneri strain which was also the same strain we isolated from the manipulators' hands. In the hand model with propofol, all bottles recovered a Micrococcus sp., which was phenotypically coincident with that isolated from the manipulators' hands. In the remaining models with $S$. aureus with both saline and propofol, the ATCC 29213 S. aureus was recovered in 18 out of the 20 bottles (Table 1).

Regarding the median (IQR) time to positivity, there were no differences in either the hand model (saline $76 \mathrm{~h}$ (65.92 to 125.01) vs. propofol $75 \mathrm{~h}$ (51.45 to 99.00), $p$ > 0.05 ) or in the $0.5 \mathrm{McFarland} S$. aureus model (saline $105 \mathrm{~h}$ (45.97 to 239.94) vs. propofol $148 \mathrm{~h}$ (66.04 to 236.58), $p$ > 0.05). In contrast, in the 0.05 McFarland S. aureus model, the median (IQR) time to positivity was significantly higher when instilling saline than when instilling propofol: $240 \mathrm{~h}$ (154.82 to 360.00) vs. $66 \mathrm{~h}$ (58.01 to 69.11), $p=0.008$. Moreover, when comparing the median (IQR) time to positivity between the three models with saline, the 0.05 McFarland S. aureus model was also significantly higher than the hands model: $240 \mathrm{~h}$ (154.82 to 360.00$)$ vs. $76 \mathrm{~h}$ (65.95 to 125.00), $p=0.016$ (Table 2, Figure 2).

Table 1 Characteristics of the experiment regarding contamination model and type of instillation fluid

\begin{tabular}{|c|c|c|c|c|}
\hline $\begin{array}{l}\text { Contamination } \\
\text { degree }\end{array}$ & $\begin{array}{l}\text { Instillation } \\
\text { fluid }\end{array}$ & $\begin{array}{l}\text { Colonizing } \\
\text { microorganisms }\end{array}$ & MTP (IQR), h & Manipulator hand flora \\
\hline \multirow[t]{2}{*}{ Hands $^{a}$} & Saline & $\begin{array}{l}\text { S. epidermidis, S. } \\
\text { warnerii }\end{array}$ & $\begin{array}{c}76.25(65.92 \text { to } \\
125.01)\end{array}$ & $\begin{array}{c}\text { S. epidermidis, S. warnerii, CoNS, SV, P. } \\
\text { acnes, Micrococcus sp. }\end{array}$ \\
\hline & Propofol & Micrococcus sp. & $\begin{array}{c}74.91(51.45 \text { to } \\
99.00)\end{array}$ & $\begin{array}{c}\text { S. epidermidis, S. warnerii, CoNS, SV, P. } \\
\text { acnes, Micrococcus sp. }\end{array}$ \\
\hline \multirow[t]{2}{*}{$0.5 \mathrm{MF} \mathrm{SA}^{\mathrm{b}}$} & Saline & $\begin{array}{l}\text { MSSA (ATCC } \\
\text { 29213) }\end{array}$ & $\begin{array}{c}104.92(45.97 \text { to } \\
239.94)\end{array}$ & NA \\
\hline & Propofol & $\begin{array}{l}\text { MSSA (ATCC } \\
\text { 29213) }\end{array}$ & $\begin{array}{c}147.89(66.04 \text { to } \\
236.58)\end{array}$ & NA \\
\hline \multirow[t]{2}{*}{$0.05 \mathrm{MF} \mathrm{SA}^{\mathrm{c}}$} & Saline & $\begin{array}{l}\text { MSSA (ATCC } \\
\text { 29213) }\end{array}$ & $\begin{array}{l}240.20(154.82 \\
\text { to } 360.00)\end{array}$ & NA \\
\hline & Propofol & $\begin{array}{l}\text { MSSA (ATCC } \\
\text { 29213) }\end{array}$ & $\begin{array}{l}66.11(58.01 \text { to } \\
69.11)\end{array}$ & NA \\
\hline \multirow[t]{2}{*}{ Control $^{d}$} & Saline & NA & NA & NA \\
\hline & Propofol & NA & NA & NA \\
\hline
\end{tabular}

${ }^{\mathrm{a}}$ Manipulation of the connector without gloves. ${ }^{\mathrm{b}}$ Manipulation of the connector with gloves impregnated with a 0.5 McFarland solution of Staphylococcus aureus ATCC 29213. 'Manipulation of the connector with gloves impregnated with a 0.05 McFarland solution of Staphylococcus aureus ATCC 29213 . ${ }^{d}$ Standard sterile manipulation with clean gloves and with disinfection of connectors using alcohol. MTP, median time to positivity; IQR, interquartile range; SA, Staphylococcus aureus; MF, McFarland; CoNS, coagulase-negative staphylococci. 
Table 2 Median time to positivity of the bottles comparing different contamination models and different fluids

\begin{tabular}{lllcr}
\hline Fluid & MTP (IQR), $\mathbf{h}$ & & $\boldsymbol{p}$ \\
\cline { 2 - 4 } & Hands & $\mathbf{0 . 5}$ MF SA & $\mathbf{0 . 0 5} \mathbf{~ M F ~ S A ~}$ & \\
\hline Saline & $76.25(65.95$ to 125.00$)$ & $104.92(45.96$ to 239.94$)$ & $240.20(154.82$ to 360.00) & $0.041^{\text {a }}$ \\
Propofol & $74.91(51.44$ to 98.99$)$ & $147.89(66.03$ to 236.58$)$ & $66.11(58.01$ to 69.11$)$ & 0.24 \\
$p$ & 0.69 & 1.00 & 0.008 & \\
\hline
\end{tabular}

${ }^{a}$ We found statistically significant differences between the $0.05 \mathrm{McF}$ arland $\mathrm{S}$. aureus model and the hand model. MTP, median time to positivity; SA, Staphylococcus aureus; MF, McFarland.

We have created an in vitro model of connector handling with gloves impregnated with a 0.05 McFarland S. aureus solution while instilling saline, lasting long enough to be used as a useful model to test the efficacy of closed needleless connectors.

Some recent in vitro studies used standard models of contamination to compare different needleless connectors against the capacity of microorganisms to ingress through the catheter lumen. However, some of them were performed using a two-phase method, in which, first, the connectors were contaminated with a single known microorganism (such as $S$. aureus or S. epidermidis, which is commonly associated to catheter infection) at different concentrations and, second, they were manipulated to instill contaminated infusion fluids $[3,4,6,7,10,11]$. But this methodology did not simulate the real practice of connector handling.

We compared two solutions of S. aureus of different concentrations by colonizing the surface of a blood culture bottle (while instilling sterile fluids), which simulates better the real daily practice, instead of instilling a contaminated fluid directly through the catheter. Besides, we tested not only a known concentration of a single known microorganism, but also the microorganisms from the flora of the manipulators' hands, as it has been demonstrated that these are highly colonized and could be a potential source of contamination [12]. With this model based on a simple daily handling, we have demonstrated that manipulation of connectors using gloves impregnated with a 0.05 McFarland solution of $S$. aureus while instilling sterile saline had longer times of positivity, allowing us to prove this model in the comparison of other types of connectors

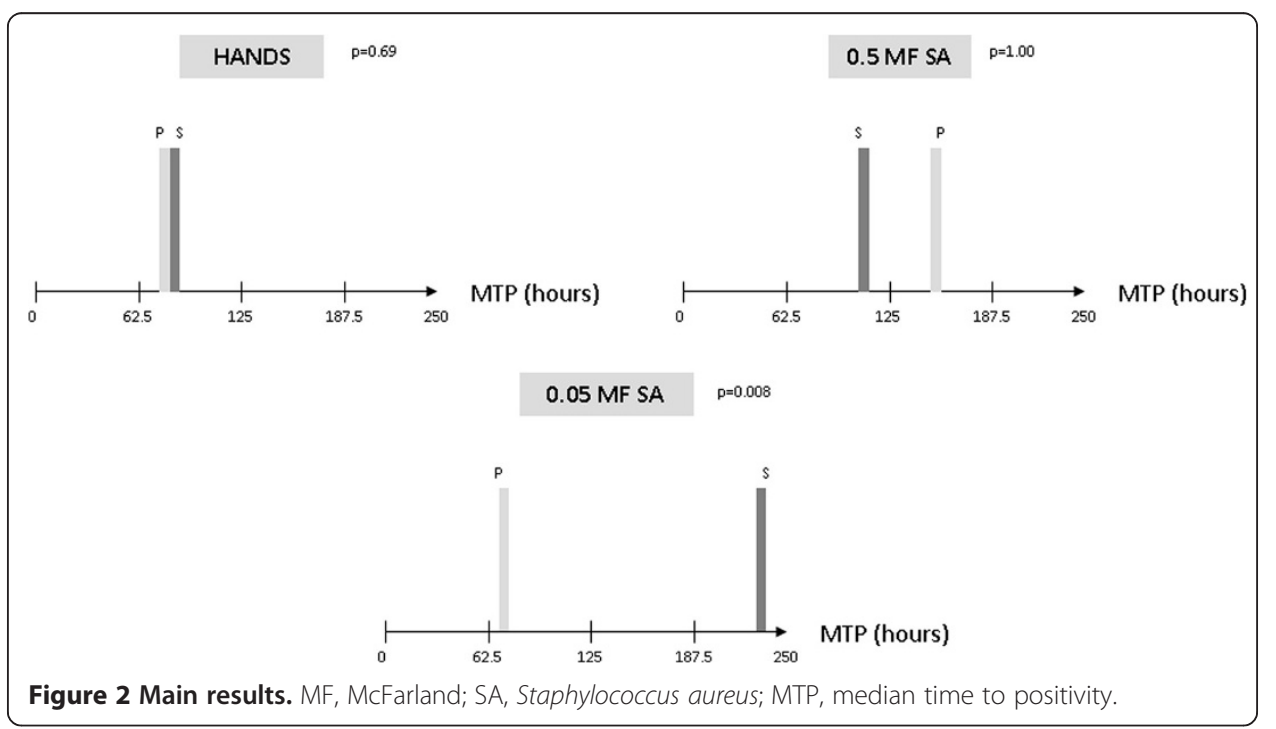


with time enough to detect differences between them regarding their efficacy to prevent the entry of microorganisms through the catheter.

Our study also supports the importance of disinfection before handling a connector, as in our model, all bottles manipulated without gloves turned positive up to 3 to 4 days after catheter insertion.

\section{Conclusions}

A daily connector handling with a 0.05 McFarland S. aureus solution while instilling saline proved to be a useful model to test the efficacy of closed needleless connectors. Future studies must be performed with a larger sample and comparing other types of connectors.

\section{Additional files}

Additional file 1: Manipulation with gloves. The manipulation model showing the handling of the bottles while instilling the fluids using gloves impregnated with the S. aureus solution.

Additional file 2: Manipulation without gloves (hands). The manipulation model showing the handling of the bottles while instilling the fluids without gloves.

\section{Abbreviations}

C-RBSI: catheter-related bloodstream infections; CRI: catheter-related infections; IQR: interquartile range.

\section{Competing interests}

This work was supported by grants from CareFusion. MG (CP13/00268) was supported by the Fondo de Investigación Sanitaria.

\section{Authors' contributions}

MG performed the study design and drafted the manuscript. MP participated in the design of the study, carried out the manipulation model, and participated in the analysis of the data. LA has been involved in the design of the study and participated in the statistical analysis. PM made substantial contributions to the acquisition of data and its interpretation. EB participated in the study design and gave the final approval of the version to be published. All authors read and approved the final manuscript.

\section{Authors' information}

MG is a young researcher at the Microbiology Department, whose main project is based on the prevention, diagnosis, and treatment of C-RBSI. MP is a research nurse from the Cardiac Surgery Postoperative Care Unit, who daily manipulates central venous catheters. LA is responsible for the BACTEC area and is a specialist in statistics. PM is responsible for the diagnosis area of catheter colonization and C-RBSI. EB is the head of the Clinical Microbiology and Infectious Diseases Department and an expert on C-RBSI.

\section{Author details}

${ }^{1}$ Department of Clinical Microbiology and Infectious Diseases, Hospital General Universitario Gregorio Marañón, C/ Dr. Esquerdo, 46, 28007 Madrid, Spain. ${ }^{2}$ Medicine Department, School of Medicine, Universidad Complutense de Madrid, Avda. Séneca, 2, 28040, Madrid, Spain. ${ }^{3}$ CIBER Enfermedades Respiratorias-CIBERES (CB06/06/0058), Madrid, Spain. ${ }^{4}$ Cardiac Surgery Postoperative Care Unit, Hospital General Universitario Gregorio Marañón, C/ Dr. Esquerdo, 46, 28007, Madrid, Spain.

Received: 5 September 2014 Accepted: 14 October 2014

Published online: 07 November 2014

\section{References}

1. Kim JS, Holtom P, Vigen C (2011) Reduction of catheter-related bloodstream infections through the use of a central venous line bundle: epidemiologic and economic consequences. Am J Infect Control 39(8):640-646

2. Mermel LA, Allon M, Bouza E, Craven DE, Flynn P, O'Grady NP, Raad II, Rijnders BJ, Sherertz RJ, Warren DK (2009) Clinical practice guidelines for the diagnosis and management of intravascular catheter-related infection: 2009 update by the Infectious Diseases Society of America. Clin Infect Dis 49(1):1-45

3. Menyhay SZ, Maki DG (2008) Preventing central venous catheter-associated bloodstream infections: development of an antiseptic barrier cap for needleless connectors. Am J Infect Control 36(10):S174, e1-5

4. Yebenes JC, Delgado M, Sauca G, Serra-Prat M, Solsona M, Almirall J, Capdevila JA, Balanzó X (2008) Efficacy of three different valve systems of needle-free closed connectors in avoiding access of microorganisms to endovascular catheters after incorrect handling. Crit Care Med 36(9):2558-2561

5. Casey AL (2012) A laboratory comparison of microbial ingress into eight different needleless IV access devices, IDWeek. October 17-21. San Diego, CA, Poster No. 896 
6. Pulcini D (2012) Evaluation of fluid path colonization in needle-free connectors and biofilm formation in central venous catheters, Poster No 275 at Biofilms Congress of the American Society of Microbiology (ASM)

7. Ryder M (2007) Transferencia De Bacterias A Través De Conectores Sin Aguja: Comparación De Nueve Dispositivos Diferentes, Poster No 412 at Congress of the Society for Healthcare Epidemiology of America (SHEA)

8. Ryder M (2012) Comparison of bacterial transfer and biofilm formation on intraluminal catheter surfaces among eight needleless connectors in a clinical simulated in vitro model, Poster at 38th Annual Canadian Vascular Access Association Conference

9. Baron EJ WM DW, Yagupsky P, Welch DF, Wilson DM (2005) Blood cultures IV. American Society for Microbiology, Washington DC

10. Menyhay SZ, Maki DG (2006) Disinfection of needleless catheter connectors and access ports with alcohol may not prevent microbial entry: the promise of a novel antiseptic-barrier cap. Infect Control Hosp Epidemiol 27(1):23-27

11. Yebenes JC, Martnez R, Serra-Prat M, Sauca G, Capdevila JA, Balanzo X, Palomar M (2003) Resistance to the migration of microorganisms of a needle-free disinfectable connector. Am J Infect Control 31(8):462-464

12. Pancholi P, Healy M, Bittner T, Webb R, Wu F, Aiello A, Larson E, Latta PD (2005) Molecular characterization of hand flora and environmental isolates in a community setting. J Clin Microbiol 43(10):5202-5207

doi:10.1186/s40635-014-0027-9

Cite this article as: Guembe et al: A simple and easy in vitro model to test the efficacy of IV lines' needleless connectors against contamination. Intensive Care Medicine Experimental 2014 2:27.

Submit your manuscript to a SpringerOpen ${ }^{\circ}$ journal and benefit from:

- Convenient online submission

- Rigorous peer review

- Immediate publication on acceptance

- Open access: articles freely available online

- High visibility within the field

- Retaining the copyright to your article

Submit your next manuscript at $\boldsymbol{\sim}$ springeropen.com 